\title{
Seasonality of climate-human mortality relationships in US cities and impacts of climate change
}

\author{
Robert E. Davis $^{1, *}$, Paul C. Knappenberger ${ }^{2}$, Patrick J. Michaels ${ }^{1,3}$, \\ Wendy M. Novicoff ${ }^{4}$ \\ ${ }^{1}$ University of Virginia, Department of Environmental Sciences, PO Box 400123, Charlottesville, Virginia 22904-4123, USA \\ ${ }^{2}$ New Hope Environmental Services, 5 Boars Head Lane, Suite 101, Charlottesville, Virginia 22903, USA \\ ${ }^{3}$ Cato Institute, Washington, DC 20001-5403, USA \\ ${ }^{4}$ University of Virginia, Department of Health Evaluation Sciences, School of Medicine, Box 800717, HSC, Charlottesville, \\ Virginia 22908, USA
}

\begin{abstract}
Human mortality in US cities is highest on extremely hot, humid summer days, but in general, winter-mortality rates are significantly higher than summer rates. The observed winterdominant warming pattern, which has been linked to increasing greenhouse-gas concentrations, has led some researchers to propose future mortality decreases, while others contend that increasing heat-related mortality in summer will more than offset any winter-mortality reductions. Because winter mortality is only weakly linked to daily weather, we examine the seasonality of mortality using monthly data for 28 major US cities from 1964 to 1998. Daily all-causes mortality counts are agestandardized, aggregated monthly, and related to mean monthly 07:00 h local standard time (LST) air temperature in each city. The climate-mortality seasonality patterns are examined for spatial and temporal (decadal-scale) variability, and the impact of climate change on mortality rates is investigated after an approximation of the inherent technology/adaptation trend is removed from the monthly time series. Mortality seasonality varies little between most US cities with comparable climates. By the 1990s, monthly mortality anomalies were similar between all cities regardless of climate, suggesting there is no net mortality benefit to be derived from a location's climate. After removing the impact of long-term declining mortality rates, some statistically significant monthly climate-mortality relationships remain in most cities, with generally positive temperature-mortality relationships in summer and negative relationships in winter. Future mortality could be reduced with a winter-dominant warming but increase with pronounced summer warming. In each case, however, net future climate-related mortality rates are very low relative to the baseline death rate, indicating that climate change will have little impact in defining future mortality patterns in US cities.
\end{abstract}

KEY WORDS: Human mortality $\cdot$ Climate change $\cdot$ Seasonality $\cdot$ United States

\section{INTRODUCTION}

Future increases in human-mortality rates are among the suite of potential impacts expected to arise from anthropogenic climate warming (Kalkstein 1993, Kalkstein \& Greene 1997, National Assessment Synthesis Team 2000, IPCC 2001a). These predictions are derived from studies that have identified statistically significant historical relationships between high heat and/or humidity and mortality at many locations (e.g. Oeschli \& Buechley 1970, Bridger et al. 1976, Kalkstein \& Davis 1989, Kalkstein \& Greene 1997). In the US, this possibility is of special concern because heat is the most common weather-related cause of death (Changnon et al. 1996, Kilbourne 1997).

But mortality exhibits a strong seasonal cycle, with winter-mortality rates significantly elevated relative to summer. The observed warming in the latter half of the 

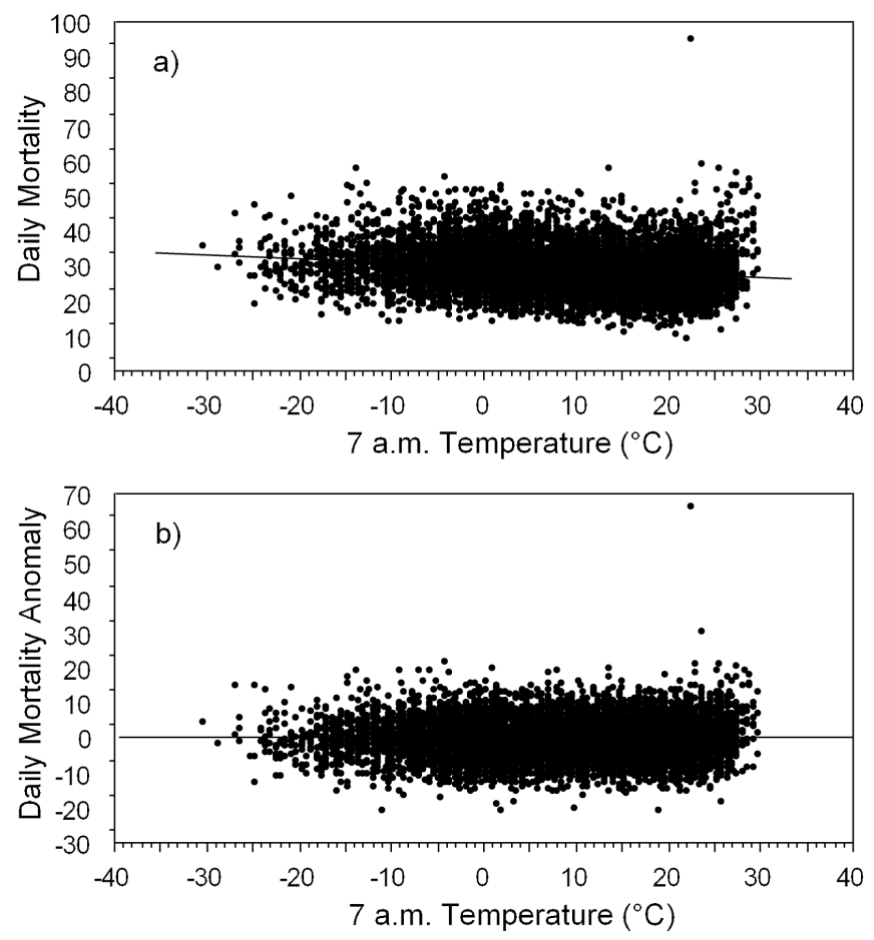

Fig. 1. (a) Population-adjusted daily mortality vs 07:00 h local standard time (LST) temperature $\left({ }^{\circ} \mathrm{C}\right)$ for the Kansas City metropolitan statistical area (MSA). A linear regression line is superimposed. (b) Same as in (a) but for de-seasoned, population-adjusted daily mortality

twentieth century has been winter dominant, and both theory and climate models suggest that this seasonal warming pattern is linked to increasing greenhousegas concentrations in the atmosphere (e.g. Michaels et al. 1998, IPCC 2001b). By coupling these seasonal warming and mortality patterns, some researchers have suggested that future mortality rates will exhibit a net decline (Bentham 1997, Moore 1998, Michaels \& Balling Jr 2000).

These divergent views are based upon fundamentally different methods of examining weathermortality relationships. Because summer heat events seem to be causally linked to increased mortality, summer mortality has garnered much of the attention of the research community, especially in the US. However, comparatively little effort has been put forth in examining the seasonality of deaths and how these seasonal variations might or might not be related to climate. Therefore, our goals are to study the seasonal mortality cycle in 28 major cities in the US, to investigate the possible role of climate in shaping this cycle, and to attempt to estimate the effect of potential climate change on future mortality rates in US cities and thereby add to the debate on possible future climate change impacts on US mortality.

\section{BACKGROUND: A DEMONSTRATION OF THE PROBLEM}

The winter dominance of mortality is widely recognized throughout the US and in many other mid-latitude countries that experience some climate seasonality (Sakamoto-Momiyama 1977, Langford \& Bentham 1995, Donaldson \& Keatinge 1997, Eurowinter Group 1997, Lerchl 1998, Laschewski \& Jendritzky 2002). Although many different causes of death exhibit this seasonality, cardiovascular and respiratory mortality seasonal variations have garnered the most attention (Donaldson et al. 1998, Eng \& Mercer 1998, Danet et al. 1999, Kloner et al. 1999, Lanksa \& Hoffmann 1999, Pell \& Cobbe 1999, McGregor 2001, McGregor et al. 2004). The seasonal component so dominates the long-term signal that it is even evident in plots of daily data. For example, Fig. 1a shows daily population-adjusted mortality (see Section 3 for details) versus morning temperature in Kansas City, Missouri, for the 10592 available days from 1964 to 1998. The subtle U-shaped relationship, with higher mortality at the tails of the distribution, is common in most mid-latitude cities. There is a pronounced increase in mortality rates associated with hot mornings and a more subdued increase in mortality on the coldest mornings. But, despite the obvious mortality peak on hot days, there is an overall statistically significant negative relationship in which winter mortality exceeds summer mortality in Kansas City by approximately 15\% (based upon an unpaired, 1-tailed, 2-sample $t$-test). This seasonality is evident and statistically significant even when the extremes of the distribution (the hottest and coldest days) are deleted. It is also noteworthy that not all of the hottest days are associated with aboveaverage death rates. In fact, many hot days exhibit below-normal mortality. One hypothesis is that these lowered death rates represent 'mortality displacement' by which the more susceptible individuals die during an extreme heat event, leaving behind a healthier population that is comparatively resistant to high heat and humidity.

Application of relationships like that depicted in Fig. 1a to a background climatic warming have led to differing views on future climate-change impacts. Research groups that predict future mortality increases focus on the summer-mortality relationship being much stronger than the winter-mortality relationship-thus proposing that summer temperature increases will raise summer deaths relative to any small mortality 'savings' that might occur with a winter warming. By contrast, those who have projected net mortality declines emphasize the overall negative relationship between temperature and mortality (focusing on the data at the monthly/seasonal rather than the daily level of specificity) and cite a preponderance of winter warming relative to summer. 
Although one of these forecasts must be correct by default, we contend that neither approach is sufficient based upon fundamental assumptions. Researchers predicting higher future mortality rates inherently assume that the time series of the weather-mortality relationship is stationary, i.e. that future relationships between hot, humid weather and mortality rates will be similar to past relationships. However, our research team has documented that these times series are, in fact, non-stationary (Davis et al. 2002, 2003a,b). Through a wide variety of adaptive and technological responses, US society has largely become desensitized to increasing heat and humidity, such that mortality rates on hot and humid days have declined significantly between the 1960s and 1990s (Davis et al. 2002, $2003 a, b)$. With the caveat that a few cities did not exhibit these mortality declines, we concluded that climate change will have little to no impact on future warm-season mortality in most US cities based on an increasing frequency or intensity of hot and humid days. Furthermore, by not explicitly accounting for mortality displacement effects, forecasts of more summer heat-related deaths are overestimates. However, mortality displacement (Gover 1938, Schuman et al. 1964, Schuman 1972, Marmor 1975, Lyster 1976, Kalkstein 1993, Kilbourne 1997, Laschewski \& Jendritzky 2002) is not a universal feature in all cities, and the topic has not been examined systematically in the US with respect to heat.

It is likewise inappropriate to assume that a winterdominant warming will save lives, because the overall mortality-temperature relationship is negative. This can be demonstrated by removing the inherent seasonality from the data. This step is necessary because a weak heat event in April, for example, might exhibit higher absolute mortality than an even stronger event in July simply because April mortality rates are higher on average. After de-seasoning the data by subtracting from each observation the median mortality rate for the month in which it occurred, the summer mortality peak becomes even more pronounced but the winter peak is diminished (Fig. 1b). This result, which is consistent across all cities examined, suggests that there is little relationship between daily weather and mortality in the winter despite winter's higher overall death rate. Although some winter research has uncovered relationships between extreme cold and mortality at time lags of 1 wk or more (Laschewski \& Jendritzky 2002), the excess mortality is small and the relationship does not seem to be universal (Glass \& Zack 1979, Larsen 1990a,b, Frost \& Auliciems 1993, Gorjanc et al. 1999). These seasonal-mortality patterns produce the apparent quandary that, whereas cold days are not associated with high mortality, winter months are. While there are some potential explanations for this (see
Section 6.2), it is clear that the fundamental nature of weather-mortality relationships differs between summer and winter. Therefore, from the perspective of daily weather events, the conclusion that future winter mortality will decline simply because winters will be warmer seems unfounded.

In this research, we examine relationships between mortality and temperature seasonality in 28 major US metropolitan areas using monthly data. There are both advantages and disadvantages to performing this research at the monthly time scale. Given the lack of any clear daily linkages between cold-season weather and mortality, use of the longer, monthly time-scale could identify some general underlying relationships between mortality and climate. Although this approach is clearly not preferable in summer in light of the well-known impact of individual heat events on mortality, monthly data are beneficial for eliminating possible biases related to mortality displacement, as often it is difficult to clearly delineate the beginning and end of high-temperature events using daily meteorology and mortality data. Therefore, integration of mortality data over longer time periods (months) may provide better estimates of the net impact of daily weather events, although the identification of specific weather events becomes much more difficult (i.e. is a 'warm' month one with moderately elevated temperatures on every day, or one with several extremely hightemperature events with the remainder of the days being near normal?).

The goals of this research are (1) to explore the spatial patterns of climate-mortality seasonality in major US cities; (2) to examine whether and how mortality seasonality has changed over time; and (3) to offer some insight on future net mortality changes that might arise under different seasonal patterns of climate change.

For clarity purposes, this paper is organized in a nontraditional format. Research related to each of the goals is described in detail in separate sections (4 to 6), each of which include distinct methods and results/ discussion subsections. The implications of the overarching findings are then summarized in a single conclusions section (7).

\section{DATA AND METHODS}

Daily total deaths from all causes are extracted from National Center for Health Statistics (NCHS) archives (National Center for Health Statistics 1998). Data are organized into metropolitan statistical areas (MSAs) that include the city center and the surrounding counties that comprise the urban ring. MSAs are defined by the counties linked to each city in the 1990 definition; 
Table 1. Meteorological stations associated with each metropolitan statistical area (MSA), station abbreviations used in this study, and the WBAN (Weather Bureau Army Navy) number associated with each station

\begin{tabular}{|lrl|}
\hline Abbreviation & WBAN number & \multicolumn{1}{c}{ Meteorological station } \\
\hline ATL & 13874 & Atlanta Hartsfield International Airport \\
BAL & 93721 & Baltimore-Washington International Airport \\
BOS & 14739 & Boston Logan International Airport \\
BUF & 14733 & Buffalo Niagara International Airport \\
CHI & 94846 & Chicago O'Hare International Airport \\
CHL & 13881 & Charlotte Douglas International Airport \\
CIN & 93814 & Cincinnati Northern Kentucky Airport \\
CLE & 14820 & Cleveland Hopkins International Airport \\
DAL & 03927 & Dallas-Fort Worth International Airport \\
DEN & 23062 & Denver Stapleton International Airport/ \\
& & Denver International Airport \\
DET & 94847 & Detroit Metropolitan Airport \\
HOU & 12960 & Houston Bush Intercontinental Airport \\
KSC & 03947 & Kansas City International Airport \\
LAX & 23174 & Los Angeles International Airport \\
MIA & 12839 & Miami International Airport \\
MIN & 14922 & Minneapolis-St. Paul International Airport \\
NEW & 12916 & New Orleans International Airport \\
NOR & 13737 & Norfolk International Airport \\
NYC & 14732 & New York Laguardia Airport \\
PHI & 13739 & Philadelphia International Airport \\
PHX & 23183 & Phoenix Sky Harbor International Airport \\
PIT & 94823 & Pittsburgh International Airport \\
POR & 24229 & Portland International Airport \\
SEA & 24233 & Seattle-Tacoma International Airport \\
SFC & 23234 & San Francisco International Airport \\
STL & 13994 & St. Louis Lambert International Airport \\
TAM & 12842 & Tampa International Airport \\
WDC & 13743 & Washington Reagan National Airport \\
& & \\
\hline
\end{tabular}

from 1960, 1970, 1980, 1990 and 2000 and linearly interpolated for each intervening year (US Department of Commerce, 1973, 1982, 1992, 2001). The resulting standardized death total represents the daily number of deaths per standard million population. These standardized daily mortality totals are then averaged by month. All of the subsequent analyses in this paper utilize standardized deaths (per standard million) - we therefore use the terms mortality 'counts' and 'rates' interchangeably.

Weather data are extracted from a first-order (hourly) National Weather Service recording station within each MSA (National Climatic Data Center 1993, 1997, National Environmental Satellite, Data, and Information Service 2000). No consideration is given for possible climatic biases arising from increased urbanization over time, since the weather observations within each MSA should approximate the ambient conditions actually experienced by MSA residents. In this study, our independent variable of choice is air temperature at 07:00 h local standard time (LST; within a given time zone and neglecting Daylight Savings Time). Although it is difficult to select one variable to represent weather influences on mortality that would be applicable in both sum-

this ensures a temporally consistent MSA definition over time. Mortality data are extracted from 1964 (the start of the daily archive) through 1998 (the last year available in digital form), except for 1967-1972, when the data were incomplete. The resulting data set includes 29 years of daily mortality data for 28 of the largest MSAs in the continental US (Table 1, Fig. 2).

Variations in the age-structure within a given city over time produce fundamental changes in the death rate. Furthermore, different MSAs have inherently different age demographics. To allow for both inter- and intra-MSA comparisons, daily mortality counts are standardized using a direct standardization method commonly employed by epidemiologists (Anderson \& Rosenberg 1998). Specifically, each daily death total is age-standardized relative to a standard population, in this case the average population distribution for the entire US in 2000 (Anderson \& Rosenberg 1998). Our standardization employs population counts within 10 age categories extracted from the US Census records mer and winter, morning surface air temperature is our compromise choice. Summer weather stress indices typically incorporate both air temperature and humidity, but the air usually becomes saturated by early morning in most of the US in summer (dewfall is common), so 07:00 h LST temperature is quite often equal to 07:00 h LST dew-point temperature (Hayden 1998). Morning dew-point temperature has been identified as a key mortality indicator in prior research (Kalkstein \& Davis 1989, Smoyer et al. 2000), so in summer, 07:00 h LST air temperature is also a proxy for moisture. In winter, most daily biophysical indices incorporate some version of wind speed along with air temperature (Steadman 1971, Osczevski 1995, Quayle \& Steadman 1998, Bluestein \& Zecher 1999). However, our analysis is at the monthly rather than daily scale, so mean wind speed adds little intrinsic value. Our use of 07:00 h LST temperature is an approximation of the average time of daily minimum temperature in winter. During a period from the mid-1960s to the late 1970s, many first-order 


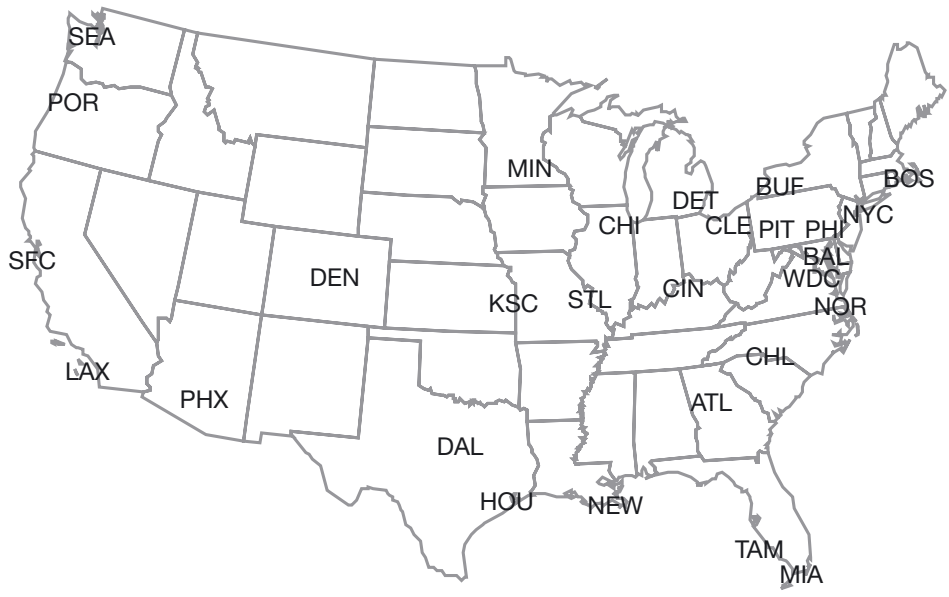

Fig. 2. Locations of the MSAs used in this study. See Table 1 for station abbreviations

weather stations collected data only at $3 \mathrm{~h}$ intervals. Because observations were not gathered at 07:00 h LST in some time zones, the 07:00 h LST temperature values were linearly interpolated from the available observations. This could introduce a small bias in 9 stations within the Central and Mountain time zones, but observation frequencies shifted from $3 \mathrm{~h}$ to hourly in many cities by the 1970 s, so the overall impact of this interpolation error is small.

For each of the 28 MSAs, we relate monthly mean standardized mortality (deaths per standard million) to monthly mean 07:00 h LST air temperature. More complete details on these data sets and the standardization procedure can be found in Davis et al. (2002, 2003a,b).

\section{MORTALITY SEASONALITY}

Our first goal is to examine mortality seasonality in 28 MSAs and to investigate any link between mortality seasonality and temperature.

\subsection{Methods}

Our daily mortality dataset includes information on the primary cause of death as assigned to 1 of the 17 general disease categories identified in the International Classification of Diseases (Versions 8 and 9). The disease-specific death rates are averaged over the period of record on a monthly basis across all 28 cities to examine US disease seasonality. A simple disease seasonality index is developed by calculating the percentage change in winter mortality (December, January, and February average) above the summer (June, July and August average) baseline.
For each MSA, mortality within the 17 disease categories is combined to produce a single all-causes average daily mortality value for each month averaged over the period of record. Then for each MSA, mortality is plotted against the climatological average monthly 07:00 h LST air temperature (12 data points for each of 28 MSAs). Even after age-standardization, differences in deaths rates across cities can complicate interpretation. Therefore, for each city, mean monthly death rates are converted to mean monthly mortality anomalies by subtracting the annual mean mortality from each monthly value. Thus, the mortality for all of the MSAs is directly comparable. Linear least-squares regressions are run both within cities ( $\mathrm{N}=12$ months) and across cities within months ( $\mathrm{N}=28 \mathrm{MSAs})$ to fully examine mortality seasonality. In these and all other analyses, we test the null hypothesis of a regression slope equal to zero using a 0.05 Type I error rate. Regression analysis is applied here to illustrate the relationships between variables - these results are not used for prediction.

\subsection{Results and discussion}

The seasonality of specific diseases, averaged over the 28 MSAs in this analysis, is presented in Table 2 (table values represent winter increases in mortality rates relative to a summer baseline). Eleven of the 17 categories demonstrate at least a $10 \%$ increase in winter mortality relative to summer, and 4 disease classes (diseases of the circulatory, respiratory, and nervous systems and mental disorders) show a more than $20 \%$ winter increase. As circulatory and respiratory disorders are the first and third leading causes of death in the US, their seasonality dominates all-causes seasonality. Neoplasms, the second leading cause of death, has a very small seasonal component (3.1\%). It is interesting that category 15, perinatal mortality, is higher in summer than in winter, in contrast to most other categories. Although this may be an artifact of higher summer birth rates and a reflection of the changing seasonal sample size (Cesario 2002), this topic merits further study because of its potential public health implications but lies beyond the scope of this research.

A plot of monthly mortality anomaly versus mean monthly 07:00 h LST temperature exhibits a very strong inverse relationship (Fig. 3). It is a characteristic of the US population that winter mortality greatly exceeds summer mortality. The monthly variance of winter mortality is higher than in summer, partly because of the higher winter death rates and the possi- 
Table 2. Seasonality index of US mortality for 17 primary causes of death from 1973-1998. Mortality data are derived from the 28 cities used in the study. The seasonality index is the percentage increase in winter (December-February) mortality above summer (June-August) mortality. The 17 disease categories are based upon versions 8 and 9 of the International Classification of Diseases (ICD-8 and ICD-9)

\begin{tabular}{|c|c|c|c|}
\hline Cause of death (disease category) & $\begin{array}{l}\text { Disease } \\
\text { class }\end{array}$ & $\begin{array}{l}\text { Average daily mortality } \\
\text { (per standard million) }\end{array}$ & $\begin{array}{l}\text { Seasonality } \\
\text { (\% increase) }\end{array}$ \\
\hline Infectious and parasitic diseases & 1 & 0.583 & 13.45 \\
\hline Neoplasms & 2 & 6.230 & 3.06 \\
\hline Endocrine, nutritional, and metabolic diseases, and immunity disorders & 3 & 0.755 & 19.78 \\
\hline Diseases of the blood and blood-forming organs & 4 & 0.107 & 8.87 \\
\hline Mental disorders & 5 & 0.309 & 24.77 \\
\hline Diseases of the nervous and sense organs & 6 & 0.426 & 24.01 \\
\hline Diseases of the circulatory system & 7 & 13.196 & 21.59 \\
\hline Diseases of the respiratory system & 8 & 2.129 & 49.97 \\
\hline Diseases of the digestive system & 9 & 1.053 & 11.51 \\
\hline Diseases of the genitourinary system & 10 & 0.506 & 19.18 \\
\hline Complications of pregnancy, childbirth, and the puerperium & 11 & 0.004 & -0.41 \\
\hline Diseases of the skin and subcutaneous tissue & 12 & 0.052 & 11.21 \\
\hline Diseases of the musculoskeletal and connective tissue & 13 & 0.092 & 16.22 \\
\hline Congenital anomalies & 14 & 0.179 & 3.61 \\
\hline Certain conditions originating in the perinatal period & 15 & 0.259 & -10.27 \\
\hline Symptoms, signs, and ill-defined conditions & 16 & 0.331 & 19.38 \\
\hline Injury and poisoning & 17 & 1.755 & -4.41 \\
\hline
\end{tabular}

ble influence of cold-season diseases like influenza (see Section 6.2).

To investigate mortality seasonality at the MSA level, we examine the relationship between monthly average 07:00 h LST temperature and the monthly average mortality anomaly by calculating the best-fit linear regression within each MSA (Fig. 4). Because the $y$-axis depicts mortality anomalies constructed individually for each MSA, and since winter mortality exceeds summer mortality, most cities have more months with negative than positive mortality anomalies. The variability in the $x$-direction is purely a function of climate. The slope for each MSA indicates the mortality sensitivity of the population to changes in temperature over the course of the year. Cities with the steepest negative slopes (such as San Francisco, Los Angeles, Miami) are cities with little seasonal temperature variation and thus an apparent greater mortality response to month-to-month temperature differences. Cities with the shallowest negative slopes (such as Minneapolis, Chicago, Detroit) have large intrannual temperature variations and a low mortality response to monthly temperature differences. The remaining cities fall in between these extremes.

Another way to examine mortality seasonality is to compare mortality in different cities within a given month (Fig. 5). Using the same dataset, the betweencity regressions show the relationship between air temperature and mortality for each month. The statistically significant positive slopes (increasing mortality with increasing temperature) for January, February, and March indicate that winter-mortality rates are significantly higher in warm cities than in cold ones. Conversely, the significant negative slopes for May, June, September, October, and November suggest that mortality rates in these months are lower in warmer locales. This result implies that, in general, cities with warmer winters have a greater annual mortality amplitude than colder cities. However, this result must be viewed with caution, because the $y$-axis contains mortality anomalies standardized for each MSA by the annual mean. Thus, a city with a high winter-mortality anomaly must also have a large summer-mortality anomaly and a large seasonalmortality amplitude because of the standardization procedure.

\section{TEMPORAL SEASONALITY CHANGES}

An initial interpretation of Fig. 5 suggests that winter warming results in higher mortality and spring and autumn warming result in lower death rates. But that analysis contains no temporal component. To properly analyze the potential impact of climate change, it is necessary to consider whether the relationships depicted in Fig. 5 are stable over time. Therefore, our second goal is to determine whether the monthly patterns of mortality-climate seasonality have changed at the decadal scale. 


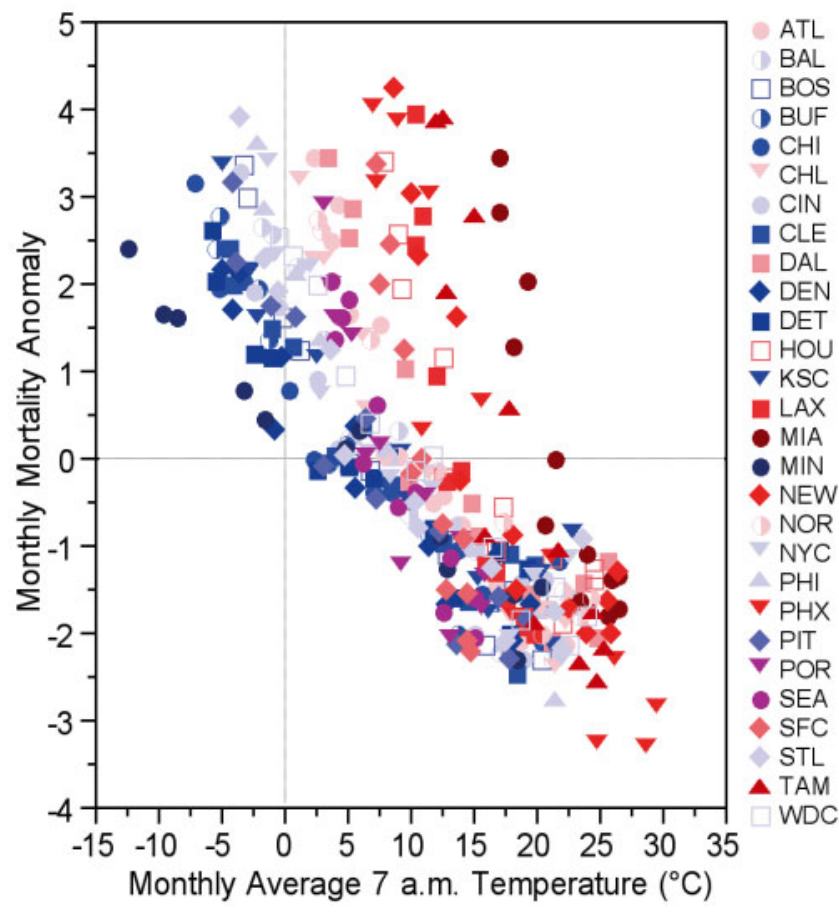

Fig. 3. Scatter plot of mean monthly mortality anomaly vs monthly average 07:00 h LST temperature $\left({ }^{\circ} \mathrm{C}\right)$ for each MSA. Each point depicts the mortality anomaly for a given MSA and month and a unique symbol is used for each MSA (see key)

\subsection{Methods}

To examine temporal changes in mortality seasonality, the data used in Fig. 5 are subdivided into 3 decades: the '1960s-1970s' (10 years; 1964-1966 and 1973-1979); the '1980s' (10 years; 1980-1989); and the '1990s' (9 years; 1990-1998). Monthly least-squares linear regression analyses are utilized once again, but in this case the analyses are run separately for each decade to determine whether decadal-scale changes in mortality seasonality are evident.

\subsection{Results and discussion}

Examination of the within-month relationships computed separately by decade shows evidence of significant changes over time. Fig. 6 presents the slope of the regression lines when the overall relationship in Fig. 5 is calculated separately for each decade. The months with positive slopes, December-March, exhibited some significant positive mortality-temperature relationships in the 1960s-1970s and 1980s but none in the 1990s. Similarly, in April, May, June and September, the significant negative relationships in earlier decades are no longer evident in the 1990s. Only 2 months, October and November, have statistically sig-

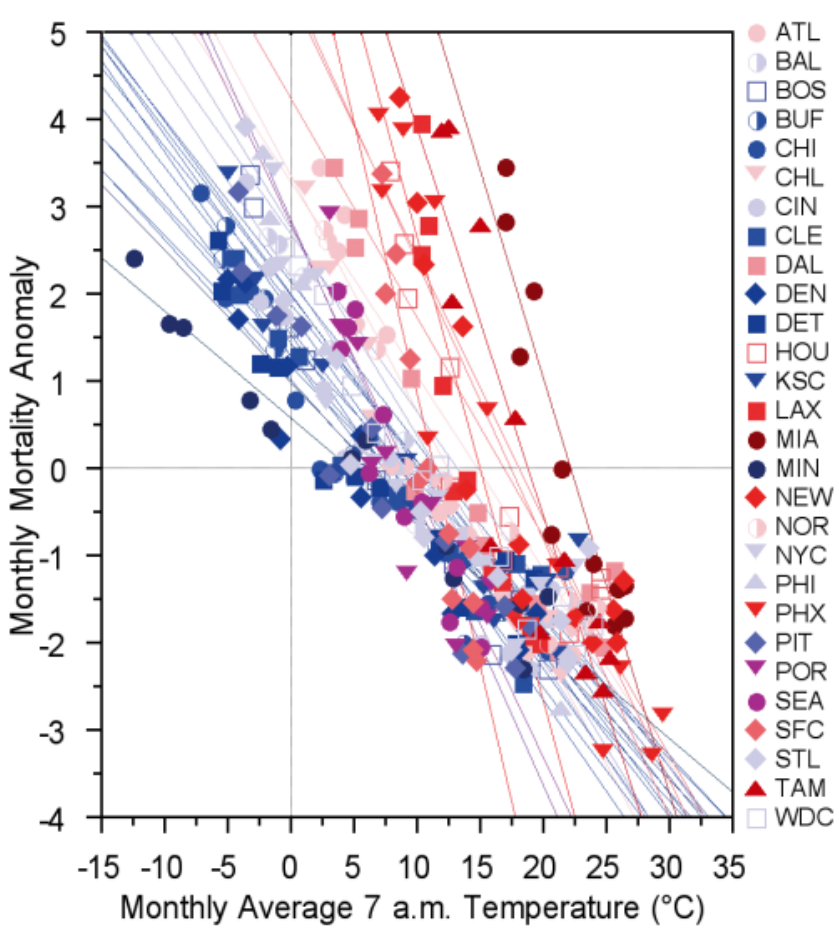

Fig. 4. Scatter plot of mean monthly mortality anomaly vs monthly average 07:00 h LST temperature $\left({ }^{\circ} \mathrm{C}\right)$ for each MSA month, showing best-fit linear regression lines within each of the 28 MSAs ( $\mathrm{N}=12$ for each regression)

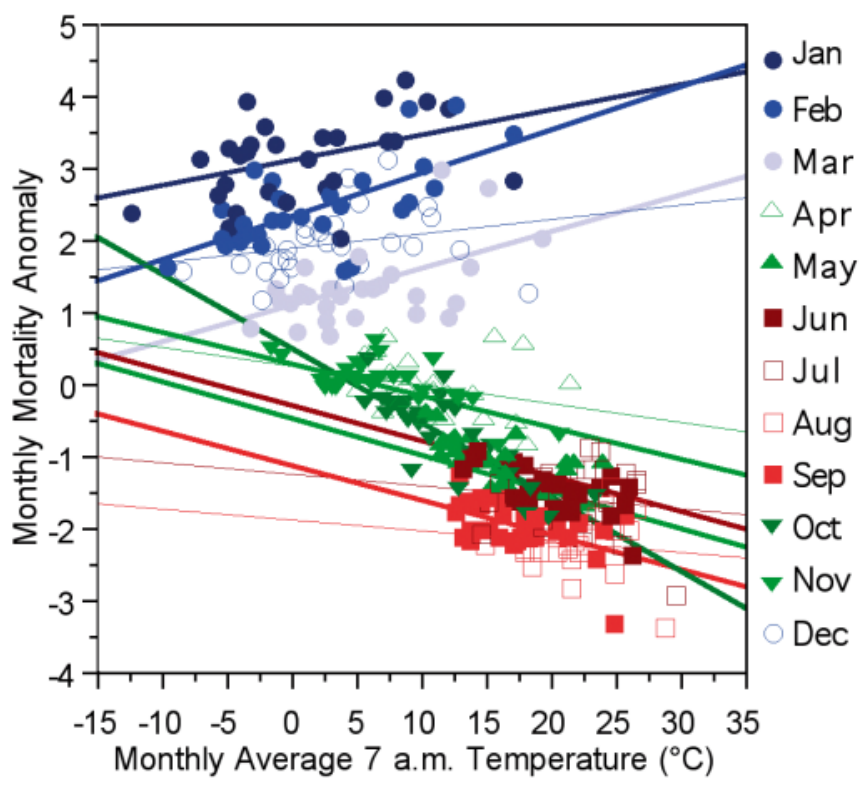

Fig. 5. Scatter plot of mean monthly mortality anomaly vs monthly average 07:00 h LST temperature $\left({ }^{\circ} \mathrm{C}\right)$ for each MSA, showing best-fit linear regression lines within month across the 28 MSAs depicting the varying monthly relationship between mortality anomaly and temperature for all MSAs in the study. Statistically significant monthly regressions are indicated by a thicker line. Each month is indicated using a unique symbol (see key) 


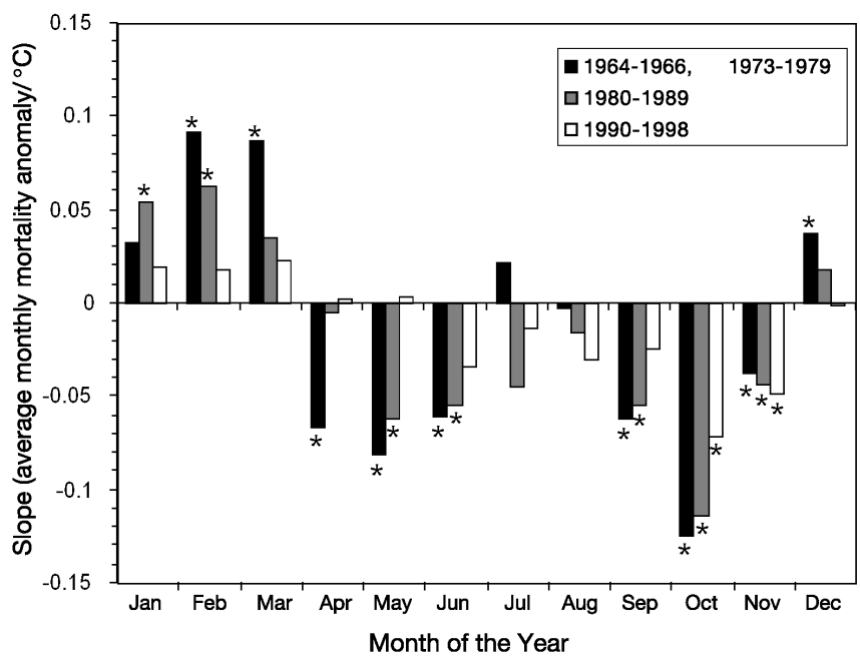

Fig. 6. Slope of the best-fit least-squares regression line between the average monthly mortality anomaly vs 07:00 h LST temperature $\left({ }^{\circ} \mathrm{C}\right.$ ) across all $28 \mathrm{MSAs}$ for each month and decade. * Statistically significant regression slope

nificant mortality-temperature slopes in the 1990s. From the 1960s through the 1980s, MSAs with higher average December-March temperatures had greater mortality anomalies than MSAs with lower average temperatures. Conversely, from April-June and September-November, warmer cities had comparably lower mortality. But almost all of these relationships were no longer apparent by the 1990s. Thus, over time, the strength of the relationship between monthly mortality anomalies and temperatures between US cities has become muted.

Because few of the slopes differ in the 1990s, this result suggests that there are few intercity (or climaterelated) differences in mortality seasonality across the US - in other words, the average annual mortality cycle, which is similar across US cities, is largely independent of climate. The overarching implication of this result indicates that there is no net mortality benefit to one's place of residence derived from the location's climate. This finding is apparently contrary to the general perception within the populace that one's longevity can be increased by moving to warmer locales. (It is interesting that Laschewski \& Jendritzky (2002) found that in Germany, on a weekly scale, transitions toward cooler conditions within all seasons resulted in lower mortality rates.) While there may be other longevity benefits to be derived from one's location that are distinct from climate, the data for the 1990s indicate little seasonal difference in mortality rates between US cities.

This result also calls into question the approach that has been used to determine climate-change impacts by identifying 'surrogate' cities whose projected future climates most resemble the contemporary climates of some cities (National Assessment Synthesis Team 2000). For example, if in the future the climate of Charlotte (North Carolina) is expected to become more like Atlanta's (Georgia) current climate, one might consider using the regression relationships from Atlanta to project Charlotte's future mortality seasonality for each month. But this approach is problematic in several different ways. First, it implies that the mortality response to heat of the populace in surrogate cities is comparable to that of the base city. But differences in urban infrastructure, health care, housing types, etc., all impact mortality rates (Smoyer 1993). Second, this method implicitly assumes that future weathermortality relationships will be comparable to the average, past relationships (i.e. that the time series of the mortality response to weather is stationary). Our prior research demonstrates that this assumption is invalid in US cities (Davis et al. 2002, 2003a,b). Third, by the 1990s, the monthly mortality-temperature relationships were almost identical in most MSAs.

Thus, there is little merit in the 'surrogate city' approach to mortality forecasting.

\section{IMPACTS OF CLIMATE CHANGE ON MORTALITY}

Our third goal is to assess the impact of climate change on observed patterns of mortality-climate seasonality and examine how potential future patterns of temperature change may influence future mortality rates.

\subsection{Methods}

We wish to investigate the sensitivity of future mortality to patterns of potential temperature change. Thus far, our analyses have been based upon annually normalized monthly mortality anomalies for each city. But these are not appropriate for projection pur-

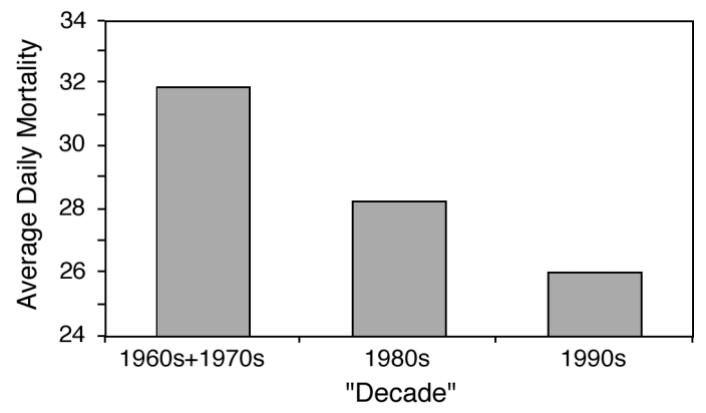

Fig. 7. Average daily total mortality, by decade, for the 28 MSAs examined in this study 


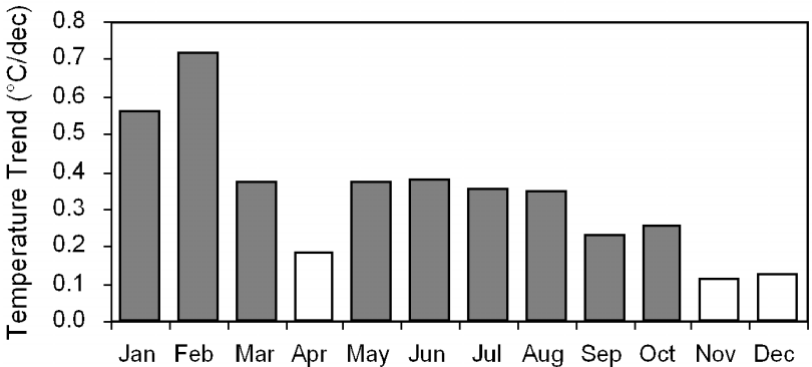

Fig. 8. Mean trend $\left({ }^{\circ} \mathrm{C} /\right.$ decade) of 07:00 h LST temperature, by month, for the $28 \mathrm{MSAs}$ in this study. Shaded bars indicate those months with statistically significant regression slopes $(\alpha \leq 0.05)$

poses because of the between-month linkage inherent in the standardization procedure used to compute mortality anomalies (i.e. a large positive January anomaly forces a large negative July anomaly). To estimate future mortality, we must examine actual mortality counts (still standardized as rates per standard million population) rather than anomalies (monthly departures). Thus, simple monthly average, age-standardized mortality counts are used in this portion of the analysis.

There has been a systematic temporal decline in adjusted death rates across all cities that is (presumably) unrelated to climate (Fig. 7). Improved health care, technological advances, reduced poverty, etc. (hereafter referred to as 'technological' influences), have resulted in greater average longevity in the US. But these declines have also taken place during a period of background climate warming. For the 28 cities in this study over our 1964-1998 period of record, 07:00 h LST temperatures have increased in all months, with the largest warming from JanuaryMarch and May-August (Fig. 8). Some component of these temperature trends may be related to increased greenhouse-gas concentrations, but they also include urbanization effects that diurnally are most evident in morning observations (e.g. Kalnay \& Cai 2003).

Because of advances in medical technology and other factors, mortality rates have declined over time across the US (Fig. 7) thereby complicating our analysis. To remove this inherent 'technological trend' from the monthly mortality data for each MSA, the annual time series for each of the 12 months is individually regressed against the annual total death rate (sum of 12 monthly values), the results of which we use as an indicator of the overall technological trend. Thus, the sample size for each of the 336 regressions $(12 \mathrm{mo} \times 28 \mathrm{MSAs})$ is $\mathrm{N}=29 \mathrm{yr}$. For all citymonths, this relationship is highly statistically significant ( $p<0.0001$ for all but 1 case). Typical examples are presented for the Kansas City MSA for January and July, respectively (Fig. 9a,b).

The residuals from this regression analysismonthly mortality departures from the technological trend line-are then regressed against 07:00 h LST temperature (again, $\mathrm{N}=29$ ) for each month (Fig. 9c,d). This analysis also requires 336 regressions representing the strength of the temperature signal in the mortality data for each month and city. Because of the small size of these samples and the higher probability that the fundamental regression assumption of independent identically distributed residuals could easily be violated, estimates of the regression slopes (betas) are bootstrapped (with replacement) 10000 times and a new frequency distribution of beta is established. Based upon the 2.5 and 97.5 percentile observations in the bootstrap sample, a determination is made for each case as to whether the mean regression slope significantly differs from zero. Any resulting significant relationships between residual mortality and temperature should therefore be largely independent of technological influences that resulted in temporally declining death rates.
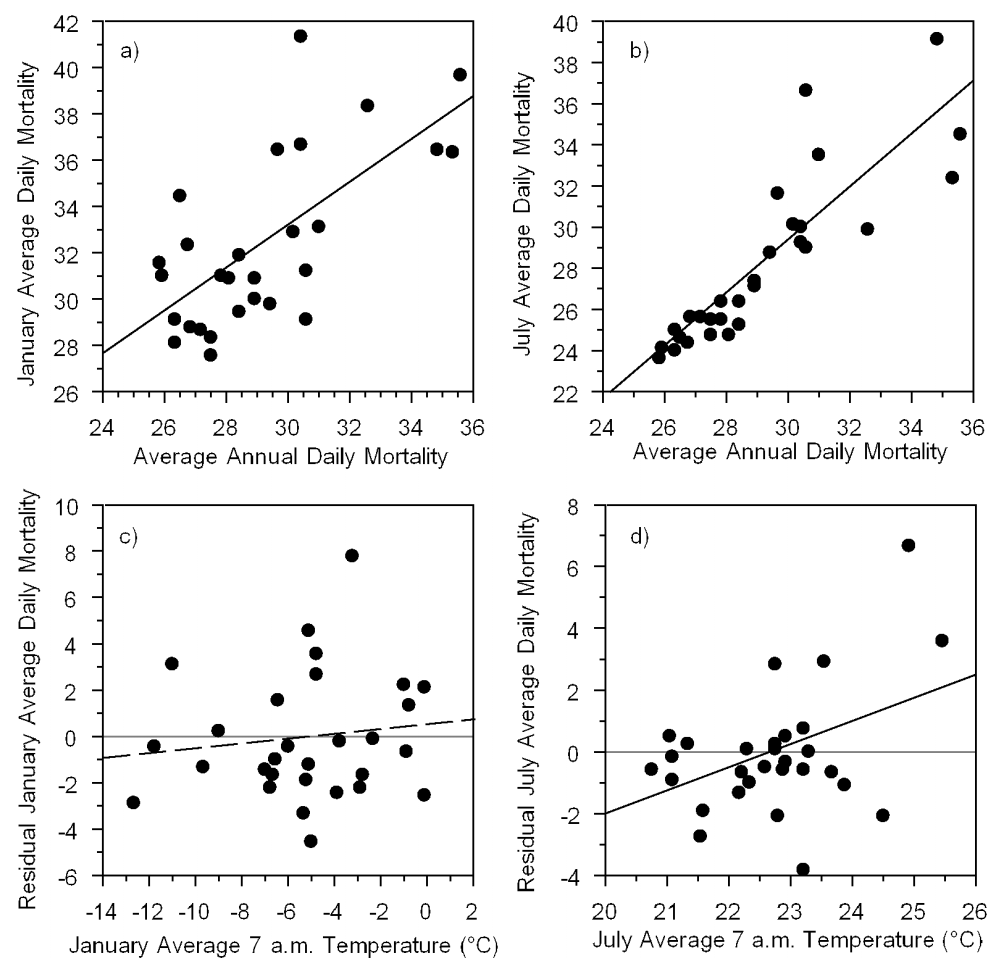

Fig. 9. $(a, b)$ Best-fit least-squares linear regression of (a) January and (b) July average mortality vs total annual mortality for the Kansas City MSA. (c,d) Linear regressions of (c) January and (d) July residuals vs 07:00 h LST temperature $\left({ }^{\circ} \mathrm{C}\right)$ for the Kansas City MSA 
Now that monthly mortality-temperature relationships have been identified for each MSA and month, independent of technological trends, it is possible to estimate the past mortality change over our period of record given the observed temperature trends and to proffer some insights on the potential impacts of future climate change. For each city-month with statistically significant mortality-temperature relationships, the slope (mean beta value from the bootstrapped distribution of betas) of the mortality-temperature regression relationship is multiplied by the observed temperature change, to produce a mortality change over the period of record.

We also use the beta values for each statistically significant city-month to estimate future mortality rates (change in deaths per decade) by multiplying the regression slopes by several different seasonal temper- ature change patterns. We apply 3 different temperature change situations to each city to demonstrate the sensitivity of the results to the seasonal patterns of potential climate change: a uniform $1^{\circ} \mathrm{C}$ warming across all months; a winter-dominant warming $\left(1.5^{\circ} \mathrm{C}\right.$ $\mathrm{mo}^{-1}$ from October-March and $0.5^{\circ} \mathrm{C} \mathrm{mo}^{-1}$ from April-September); and a summer-dominant warming $\left(1.5^{\circ} \mathrm{C} \mathrm{mo}{ }^{-1}\right.$ in the warm half-year and $0.5^{\circ} \mathrm{C} \mathrm{mo}^{-1}$ in the cold half-year). The individual city responses are then summed to produce a net national response. Our goal here is not to forecast future mortality rates but to examine the sensitivity of mortality to a few different inter-monthly patterns of temperature change. This allows us to examine the issue of how a winter warming might compensate for increased summer mortality during hot months - a topic that lies at the heart of the seasonal mortality issue.

Table 3. Beta values (slopes) of the regressions for mortality (with the technological trend removed) vs 07:00 h LST temperature for each MSA and month. Regression slopes are the means of the distribution of 10000 bootstrapped samples of beta for each MSA-month. Statistically significant slopes (2.5 and $97.5 \%$ confidence intervals) are calculated using the percentile method and indicated in bold. Marginals include counts of the number of significant and total positive and negative relationships in each column

\begin{tabular}{|c|c|c|c|c|c|c|c|c|c|c|c|c|c|c|c|c|}
\hline MSA & Jan & Feb & Mar & Apr & May & Jun & Jul & Aug & Sep & Oct & Nov & Dec & Pos. & Neg. & $\begin{array}{l}\text { Sig. } \\
\text { pos. }\end{array}$ & $\begin{array}{l}\text { Sig. } \\
\text { neg. }\end{array}$ \\
\hline ATL & -0.188 & -0.205 & -0.23 & -0.286 & -0.084 & 0.043 & 0.113 & 0.073 & -0.201 & -0.208 & -0.092 & -0.124 & 3 & 9 & 0 & 2 \\
\hline BAL & -0.056 & 0.232 & -0.208 & -0.298 & -0.166 & 0.131 & 0.45 & -0.215 & 0.046 & -0.122 & -0.038 & -0.145 & 4 & 8 & 1 & 0 \\
\hline BOS & -0.007 & 0.28 & -0.107 & -0.227 & -0.129 & 0.13 & 0.219 & 0.401 & -0.157 & -0.25 & -0.26 & -0.313 & 4 & 8 & 0 & 2 \\
\hline BUF & -0.324 & 0.209 & 0.06 & 0.007 & -0.315 & 0.155 & 0.258 & 0.328 & -0.1 & 0.063 & -0.185 & -0.189 & 7 & 5 & 0 & 2 \\
\hline $\mathrm{CHI}$ & -0.042 & 0.103 & -0.123 & -0.13 & -0.037 & 0.06 & 0.467 & 0.063 & 0.061 & -0.155 & -0.098 & -0.164 & 5 & 7 & 1 & 3 \\
\hline $\mathrm{CHL}$ & -0.214 & -0.224 & -0.342 & -0.572 & 0.132 & 0.253 & 0.243 & -0.199 & -0.103 & -0.263 & -0.107 & -0.067 & 3 & 9 & 0 & 2 \\
\hline CIN & -0.161 & -0.049 & -0.139 & 0.023 & 0.096 & 0.019 & 0.126 & 0.042 & -0.054 & -0.148 & -0.143 & -0.159 & 5 & 7 & 0 & 0 \\
\hline CLE & -0.106 & 0.019 & -0.076 & -0.063 & -0.115 & 0.167 & 0.36 & -0.0003 & 30.02 & -0.051 & -0.051 & -0.186 & 4 & 8 & 0 & 1 \\
\hline DAL & -0.154 & 0.027 & -0.012 & -0.197 & 0.111 & 0.212 & 0.581 & 0.321 & -0.111 & -0.018 & -0.163 & 0.197 & 6 & 6 & 2 & 0 \\
\hline DEN & 0.047 & 0.021 & 0.206 & -0.165 & 0.001 & -0.088 & 0.079 & -0.058 & 0.118 & -0.124 & 0.035 & 0.291 & 8 & 4 & 1 & 0 \\
\hline DET & -0.104 & 0.055 & 0.043 & -0.109 & 0.085 & 0.175 & 0.448 & 0.181 & -0.047 & -0.084 & -0.206 & -0.111 & 6 & 6 & 3 & 1 \\
\hline HOU & -0.179 & -0.18 & -0.142 & -0.087 & 0.085 & 0.071 & 0.288 & 0.541 & 0.105 & -0.113 & -0.196 & -0.3 & 5 & 7 & 1 & 2 \\
\hline $\mathrm{KSC}$ & 0.107 & -0.1 & -0.024 & -0.369 & -0.107 & -0.151 & 0.717 & -0.142 & -0.089 & -0.126 & -0.093 & -0.051 & 2 & 10 & 0 & 1 \\
\hline LAX & -0.323 & -0.41 & 0.071 & -0.166 & -0.108 & 0.037 & 0.037 & 0.243 & 0.117 & -0.065 & -0.292 & 0.04 & 6 & 6 & 1 & 1 \\
\hline MIA & -0.279 & -0.203 & 0.25 & -0.086 & -0.042 & 0.246 & -0.047 & -0.106 & 0.234 & 0.035 & -0.036 & -0.229 & 4 & 8 & 0 & 0 \\
\hline MIN & 0.019 & 0.051 & -0.108 & -0.203 & -0.036 & -0.013 & 0.163 & 0.156 & -0.118 & -0.151 & -0.028 & -0.022 & 4 & 8 & 0 & 0 \\
\hline NEW & -0.350 & -0.362 & -0.124 & -0.454 & 0.184 & 0.075 & 0.513 & 0.375 & -0.205 & -0.367 & -0.360 & -0.407 & 4 & 8 & 0 & 5 \\
\hline NOR & -0.215 & 0.147 & -0.41 & -0.08 & 0.289 & -0.071 & 0.073 & -0.086 & -0.058 & -0.128 & -0.251 & -0.254 & 3 & 9 & 0 & 0 \\
\hline NYC & -0.03 & 0.091 & -0.122 & -0.194 & 0.007 & 0.211 & 0.814 & 0.291 & -0.075 & -0.142 & -0.141 & -0.158 & 5 & 7 & 1 & 1 \\
\hline PHI & -0.135 & 0.11 & -0.166 & -0.01 & -0.144 & 0.046 & 0.468 & 0.138 & -0.026 & -0.17 & -0.212 & -0.274 & 4 & 8 & 1 & 2 \\
\hline PHX & -0.095 & -0.154 & 0.163 & -0.078 & -0.282 & -0.038 & 0.026 & -0.075 & 0.038 & 0.03 & -0.056 & 0.337 & 5 & 7 & 0 & 0 \\
\hline PIT & -0.207 & 0.004 & 0.121 & -0.461 & -0.1 & 0.064 & 0.236 & -0.044 & 0.012 & -0.133 & -0.116 & -0.154 & 5 & 7 & 0 & 1 \\
\hline POR & 0.197 & -0.56 & -0.012 & -0.309 & -0.074 & 0.096 & 0.367 & 0.597 & -0.055 & 0.109 & -0.094 & -0.17 & 5 & 7 & 1 & 2 \\
\hline SEA & -0.151 & -0.482 & -0.473 & -0.21 & -0.047 & 0.127 & 0.063 & 0.339 & 0.115 & -0.013 & 0.053 & -0.26 & 5 & 7 & 1 & 2 \\
\hline SFC & -0.386 & -0.523 & -0.249 & -0.345 & -0.079 & -0.286 & -0.008 & 0.059 & -0.011 & 0.057 & -0.146 & -0.253 & 2 & 10 & 0 & 2 \\
\hline STL & -0.072 & -0.06 & -0.098 & -0.173 & 0.011 & -0.036 & 1.52 & 0.01 & -0.043 & -0.062 & -0.075 & -0.064 & 3 & 9 & 1 & 0 \\
\hline TAM & -0.213 & -0.309 & -0.096 & -0.131 & 0.085 & 0.227 & 0.052 & 0.126 & -0.047 & -0.089 & -0.224 & -0.195 & 4 & 8 & 0 & 3 \\
\hline WDC & -0.086 & 0.261 & -0.111 & -0.059 & 0.09 & -0.149 & 0.341 & -0.005 & 0.044 & -0.133 & -0.092 & -0.054 & 4 & 8 & 1 & 1 \\
\hline Positive & 4 & 14 & 7 & 2 & 12 & 20 & 26 & 18 & 11 & 5 & 2 & 4 & 125 & & & \\
\hline Negative & 24 & 14 & 21 & 26 & 16 & 8 & 2 & 10 & 17 & 23 & 26 & 24 & & 211 & & \\
\hline Sig. pos. & 0 & 0 & 0 & 0 & 0 & 1 & 8 & 6 & 0 & 0 & 0 & 1 & & & 16 & \\
\hline Sig. neg. & 2 & 3 & 0 & 7 & 1 & 0 & 0 & 0 & 0 & 8 & 8 & 7 & & & & 36 \\
\hline
\end{tabular}




\subsection{Results and discussion}

In general, negative temperature-mortality relationships dominate in winter and positive relationships are most common in summer (Table 3, Fig. 10). Of the 336 MSA-months examined, 52 (or $15.5 \%$ ) are statistically significant, more than the number expected by random chance based on a 0.05 alpha level. There is a high degree of consistency between MSAs across months suggesting that the relationships are robust, although some false positives can still be present in the analysis. All 36 of the negative mortality-temperature relationships occurred between October and May, mostly from October through December. Similarly, of the 16 positive mortality-temperature relationships, 15 are found in June, July, and August. (The only statistically significant monthly relationship that is spatially inconsistent for a given month is the positive mortality-temperature relationship found in Denver in December.)
When the significant MSA relationships are aggregated for the US as a whole, the resulting pattern highlights the summer/winter dichotomy (Fig. 11). Warmer-than-normal summers, particularly warm Julys and Augusts, are linked to increased mortality rates. But from October through May, warmer-thannormal conditions actually reduce death rates beyond the observed reductions related to technological trends. Clearly, July is the most critical month, when 8 of the 28 MSAs have significant slopes, many of which are large in magnitude. The average of all the relationships, regardless of statistical significance, across MSAs depicts a sinusoid-like seasonality. We argue later that the significant role played by influenzarelated mortality tends to damp the real amplitude of this seasonal pattern.

Geographically, there is a monthly shift in the positive summer relationships. In July, significant positive mortality-temperature relationships are evident in
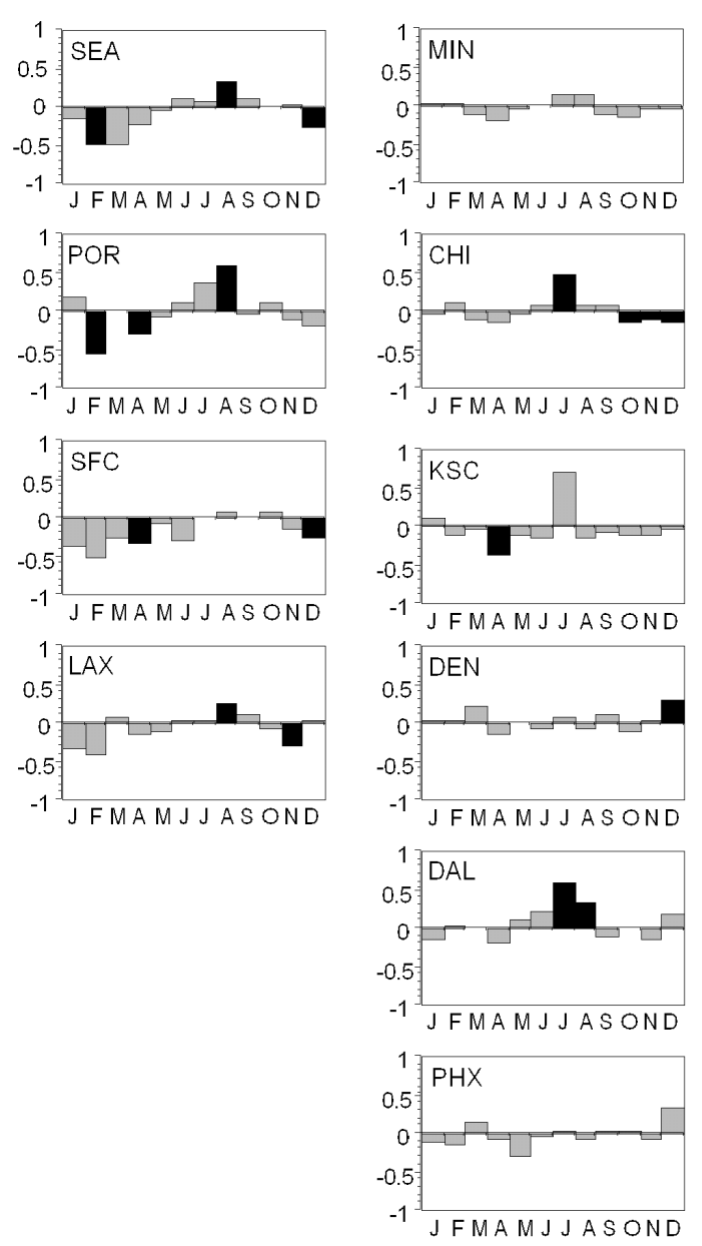
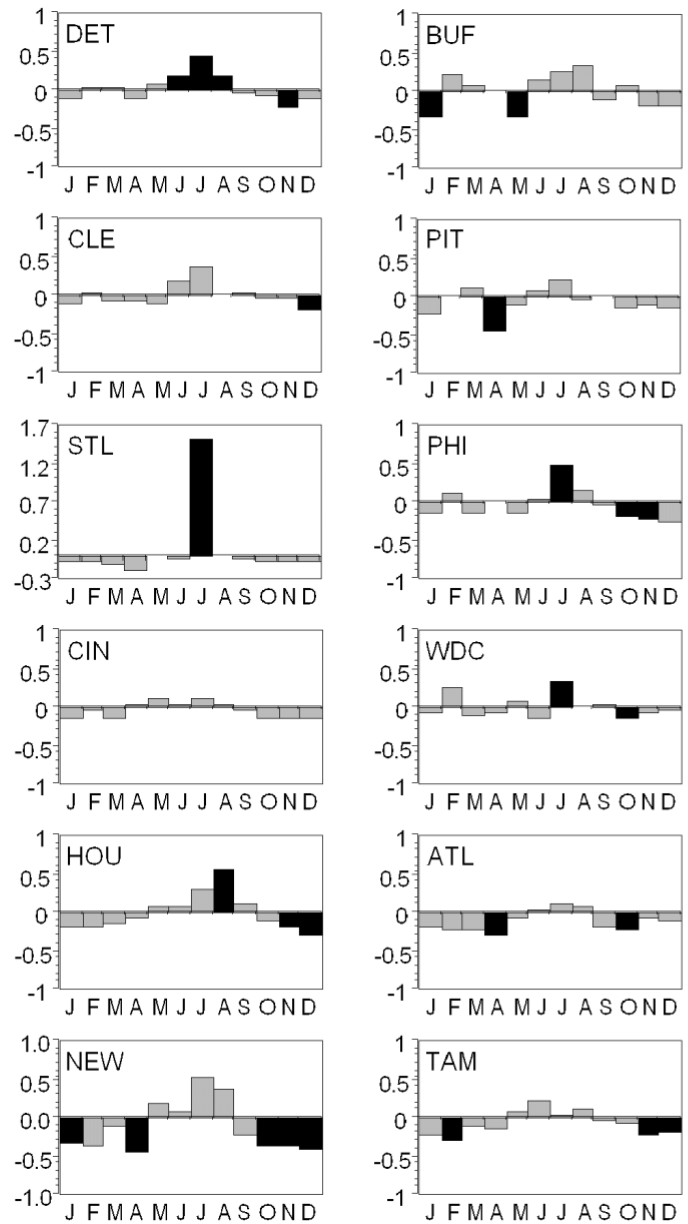
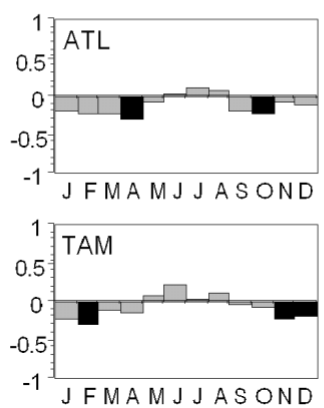
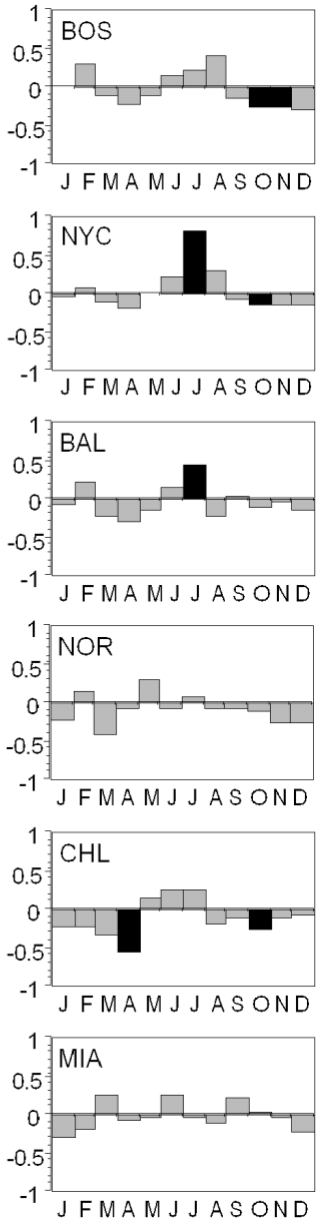

Fig. 10. Bootstrapped estimates of monthly regression slopes (excess deaths per ${ }^{\circ} \mathrm{C}$ ) of mortality (with the technological trend removed) vs 07:00 h LST temperature $\left({ }^{\circ} \mathrm{C}\right)$ for each MSA. The histograms are organized to roughly approximate the spatial distribution of the MSAs. Black bars indicate statistically significant trends (see text and Table 3) 


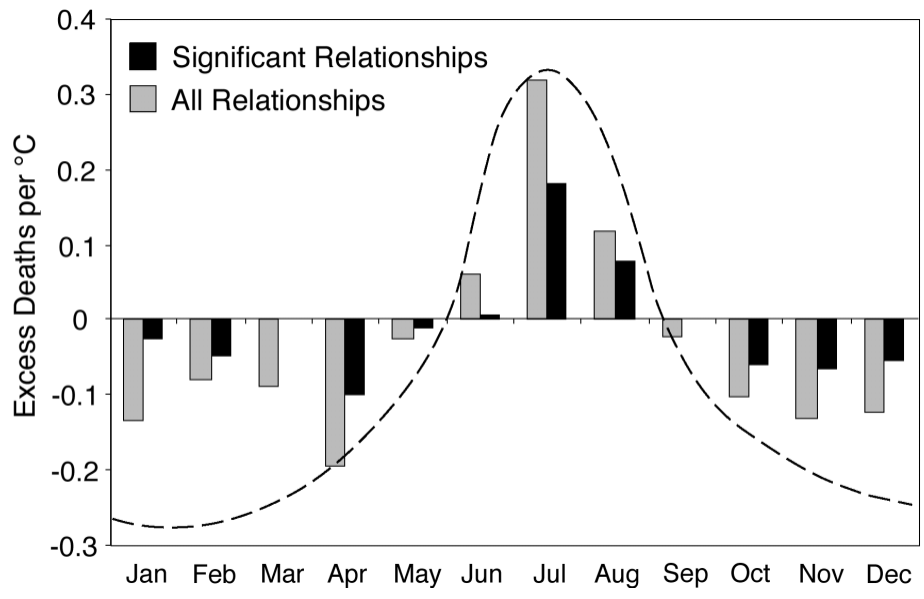

Fig. 11. Monthly average mortality-temperature relationship for the 28 study MSAs. Black histogram bars represent the average of the statistically significant relationships only (non-significant slopes are set to zero prior to calculating the mean). Grey histogram bars show the mean of all slopes regardless of significance. The superimposed curve is a hypothesized mortality-temperature seasonality relationship estimated using the months when influenza is uncommon (see text in Section 6.2)

New York, Philadelphia, Baltimore, Washington, DC, Detroit, Chicago, St. Louis, and Dallas (Fig. 10). With the exception of Dallas, all of these cities are in the northeast-north central US. Although hot and humid summer weather is not uncommon in these regions, prior research has demonstrated that cities in the northeastern quadrant of the continental US are most susceptible to summer heat mortality (Kalkstein \& Davis 1989, Davis et al. 2003a,b). In August, of the 6 cities with significant positive relationships-Detroit, Houston, Dallas, Los Angeles, Portland, and Seattle5 are located in Texas or along the West Coast. This geographic shift suggests that the nexus of summer high temperature mortality impacts can vary within season. The peak mortality in West Coast cities could be related to an increased prevalence of Santa Ana winds and their associated high temperatures. It is likewise possible that August heat events in the northeast and northern interior have a reduced impact because of 'mortality displacement' - the July heat had already resulted in excess mortality (Kalkstein \& Smoyer 1993, Kalkstein \& Greene 1997, Laschewski \& Jendritzky 2002). However, July is typically warmer than August in the southern and western MSAs as well as in the Northeast, so mortality displacement alone cannot explain this monthly geographical shift.

Interpretation is more complicated in the cold season. Winter mortality is believed to be higher because of the enhanced spread of infectious diseases as people spend more time in closer proximity, thereby increasing the infection rate (Eurowinter Group 1997). Indeed, infec- tious disease mortality is higher in winter (Table 2). Influenza and pneumonia account for over 5000 excess deaths $\mathrm{yr}^{-1}$ (Simonsen et al. 2001) and are largely responsible for the seasonality in the mortality from respiratory diseases (Table 2). However, influenza infection can result in deaths attributed to other causes, and these co-morbid factors may account for the observed seasonality in some other disease categories (Simonsen et al. 2001). Thus, part of the winter peak is directly attributable to influenza, part is related to co-morbid conditions, and part is probably unrelated to influenza in any way but simply reflects some other inherent seasonal fluctuation.

Although influenza is a winter disease, efforts to relate the strength of the flu virus or influenza-related mortality to weather and climate have been largely unsuccessful. It is not the case that severe winters have higher rates of influenza infections or mortality (Frost \& Auliciems 1993). However, influenza mortality does vary substantially from year to year (Simonsen et al. 2001), for reasons that, at present, remain unknown. Recent studies have found that influenza-related mortality rates have been increasing over time in the US (Thompson et al. 2003).

Given the lack of a relationship between climate and influenza, the temporal trend in influenza deaths, and the impact of influenza on diseases in other cause-ofdeath categories, it is difficult to fully understand the relationships between climate and mortality in winter months. In most cities, there is a strong tendency for the relationship to be negative-warm winters are associated with fewer deaths than cold winters. This tendency becomes most pronounced starting in October and continues through April, with the exception of February, which exhibits many positive and negative relationships (Table 3). In reality, the primary influenza season begins in late fall and has typically ended by March or April, if not sooner (Simonsen et al. 2001). If the influence of influenza is to mask mortalitytemperature relationships, then we might look to April as an indicator of the correct magnitude of this interaction. Using April-October as guidance, superposition of a curve on the seasonal course of climate-related mortality suggests that we are probably significantly underestimating the impact of climate on cold-season mortality (Fig. 11). However, this is mere speculation, and it may ultimately prove very difficult to effectively remove the influenza signal from the background seasonal mortality pattern in the historical time series. Obviously, there is no simple cause-effect relationship between winter mortality and the thermal environment. 


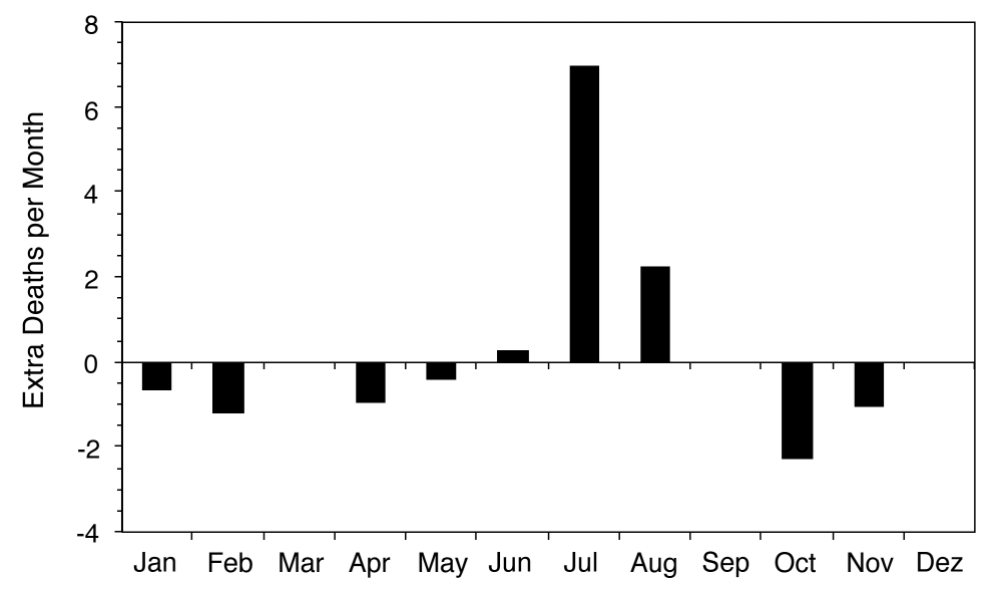

Fig. 12. Number of excess or reduced deaths, by month, at the end of the record compared with the beginning based on the observed monthly temperature trend and the statistically significant mortality-temperature relationships (Fig. 10). The relationships are derived separately for each MSA-month and then combined to produce the 28-city national average death rate of about 9500 deaths (per standard million) during the 1990s. If these projections are within an order of magnitude of the correct value, our results indicate that the observed, historical climate warming has had very little influence on human mortality rates.

Future mortality projections indicate that the monthly pattern of temperature change will be important in estimating future climate-related death rates. Using 3 simple monthly patterns of temperature seasonality, we find that a uniform $1{ }^{\circ} \mathrm{C}$ warming results in a net mortality decline of 2.65 deaths (per standard million) per MSA, the summer-dominant warming generates 3.61 additional deaths, and the winter-dominant warming produces 8.92 fewer deaths (Fig. 13). Again, these numbers are very small compared with the annual average mortality rate.

One might argue that influenza deaths be removed from the analysis a priori. Some mortality researchers chose to work specifically with diseases known to be weather-related and discard all others (e.g. Sakamoto-Momiyama 1977, Auliciems \& Skinner 1989, Seretakis et al. 1997, McGregor 1999, 2001, McGregor et al. 2004). However, significant relationships remain evident using all-causes mortality (e.g. Applegate et al. 1981, Kalkstein \& Davis 1989, Kunst et al. 1993). To date, however, it has been difficult to isolate the influence of influenza and co-morbid conditions from the mortality signal, so simple removal of deaths directly attributable to influenza will not address this problem. Even though we are knowingly including deaths that are not likely to be related to weather and climate, our approach is conservative, since this biases our analysis toward not finding significant relationships.

The observed pattern of temperature change, with a net warming of $1.16^{\circ} \mathrm{C}$ since 1964 and some warming in all months (Fig. 8), results in the excess summer deaths being partially cancelled by the reduction in winter death rates (Fig. 12). Although most of the warming has occurred from January-March, these winter months exhibit only very weak negative temperature-mortality relationships. Thus, the warming in July and August, though somewhat less than what occurred in winter, has a greater net mortality impact. The net impact of the observed temperature change over our period of record is an increase of 2.9 deaths in the annual total mortality (per standard million) per city since 1964a number that is very small relative to the annual
It is important to reiterate that our analysis was performed at a coarse monthly scale because of the lack of any strong daily relationships between mortality and weather in winter. Our goal was to examine the general seasonality of climate and mortality. A model developed to predict the number of excess deaths arising from longer or more intense heat waves, for example, might produce different mortality estimates. Clearly, there remains a net impact of heat on mortality in the US, even after removal of the long-term technological trend. However, on an annual basis, the influences of mortality displacement, mortality benefits from warmer winters, and technology tend to mitigate against summer heat mortality. This analysis, in

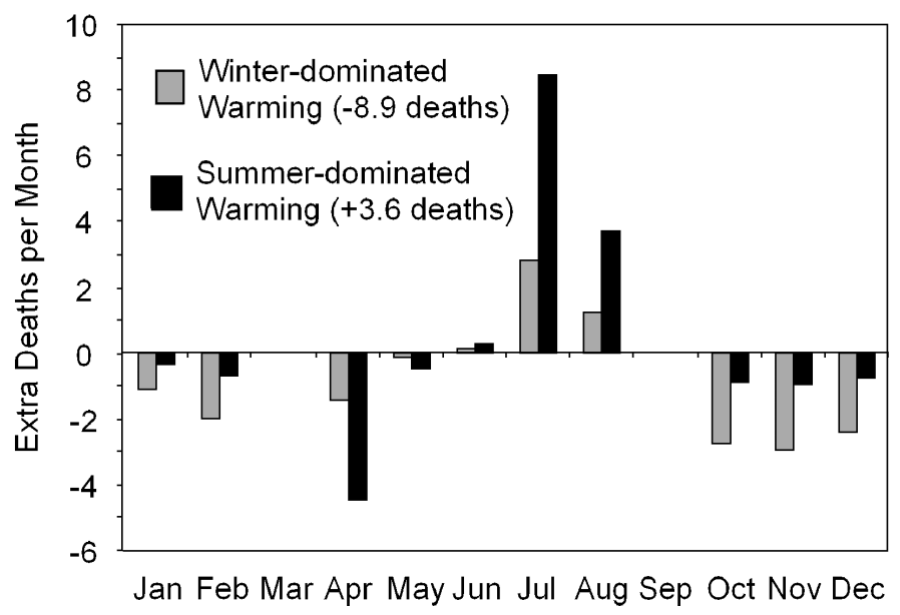

Fig. 13. Number of excess or reduced monthly deaths $\left(\mathrm{MSA}^{-1}\right)$ under 2 different climate-change scenarios, with $75 \%$ of the total annual warming in the 6 coldest months and the 6 warmest months 
which we relate mean monthly temperatures (rather than weather events) to mortality, tends to smooth over the impacts of specific events like heat waves and provides a general idea of the linkages between a warming climate and mortality patterns.

\section{CONCLUSIONS AND IMPLICATIONS}

Temperature currently does not have a major influence on monthly mortality rates in US cities. By the 1990s, there was little evidence of a net mortality benefit to be derived from one's place of residence. In all locations, warmer months have significantly lower mortality rates than colder months, undoubtedly related to the impact of influenza during the cold season, although influenza (and co-morbid influences) alone cannot account for the observed seasonality in mortality. The winter-summer mortality rate difference of residents in Phoenix or Los Angeles, for example, is similar to those of people in Minneapolis or Boston. This consistency across cites with largely different climate regimes can be partially attributed to adaptations (both biophysical and infrastructural) and influences of technology. The implication is that the seasonal mortality pattern in US cities is largely independent of the climate and thus insensitive to climate fluctuations, including changes related to increasing greenhouse gases.

Our analysis of the relationship between monthly mortality and monthly temperature after taking into account the technological influences on declining mortality rates represents one of the first efforts of its kind to assess the net impact of seasonal climate variability on mortality, although admittedly in a somewhat rudimentary manner. We find that the lives saved in conjunction with warm winters do tend to offset the additional deaths associated with warmer conditions in July and August. However, again we stress that the individual MSA plots of monthly mortality-temperature relationships (Fig. 10) provide more evidence that climate impacts on US mortality are very small. We find that the net impact of the observed temperature change from 1964 to 1998 is far less than $0.1 \%$ of the average total annual mortality in the 1990s. This implies that impacts of a future climate change that are within 1 or even 2 orders of magnitude of those observed during the past 35 yr will be very small.

Our finding of small net future mortality impacts from increasing temperatures, and of positive mortality-temperature relationships in summer and negative relationships in winter, are in general agreement with research conducted in other industrialized nations. For example, Guest et al. (1999) noted that future mortality impacts in Australia's 5 largest cities would be small by
2030. McGregor et al. (2004) found that years with strong temperature seasonality also exhibited elevated mortality from ischaemic heart disease in 5 English counties. In research conducted for Germany, Lerchl (1998) emphasized the importance of extreme cold relative to extreme heat in association with high mortality rates, although extremes also generated higher overall mortality, as in our research. But Laschewski \& Jendritzky's (2002) work in southwest Germany noted that summer heat wave mortality exceeded that associated with cold conditions in winter.

Perhaps the primary impact of our research will be to emphasize how little is known about the seasonality of mortality and its relationship to climate. Before we can begin to make confident projections of future impacts, much additional work is needed on this topic. An important component of this seasonality is the role played by climate on influenza transmission, because influenza has a major influence on higher wintermortality rates. The general lack of clear relationships between winter weather and mortality on a daily basis suggests that cold-weather events do not significantly raise mortality rates. However, in aggregate, our results indicate that cold winters do have higher net mortality than warm winters, for reasons that, at least at present, remain unknown.

Acknowledgements. We extend our thanks to Laurence S. Kalkstein, Daniel Graybeal, and Jill Derby Watts (University of Delaware) for providing the raw mortality data used in this study and for their assistance in reading the digital data sets. We also extend our heartfelt thanks to 3 anonymous reviewers, who provided exceptionally detailed and thoughtful reviews of our original submission. It is becoming increasingly rare for referees to provide this level of critique, and we appreciate their interest in our manuscript.

\section{LITERATURE CITED}

Anderson RN, Rosenberg HM (1998) Age standardization of death rates: implementation of the year 2000 standard. National Vital Statistics Reports 47(3), National Center for Health Statistics, Hyattsville, MD

Applegate WB, Runyan JW Jr, Brasfield L, Williams MLM, Konigsberg C, Fouche C (1981) Analysis of the 1980 heat wave in Memphis. J Am Geriatr Soc 29:337-342

Auliciems A, Skinner JL (1989) Cardio-vascular deaths and temperature in subtropical Brisbane. Int J Biometeorol 33: 215-221

Bentham CG (1997) Health. In: Palutikof JP, Subak S, Agnew MD (eds) Economic impacts of the hot summer and unusually warm year of 1995. Department of the Environment, Washington, DC, p 87-95

Bluestein M, Zecher J (1999) A new approach to an accurate wind chill factor. Bull Am Meteorol Soc 80:1893-1900

Bridger CA, Ellis FP, Taylor HL (1976) Mortality in St. Louis, Missouri, during heat waves in 1936, 1953, 1954, 1955 and 1966. Environ Res 12:38-48

Cesario SK (2002) The 'Christmas Effect' and other biometeo- 
rologic influences on childbearing and the health of women. J Obstetr Gynecol Neonatal Nurs 31:526-535

Changnon SA, Kunkel KE, Reinke BC (1996) Impacts and responses to the 1995 heat wave: a call to action. Bull Am Meteorol Soc 77:1496-1506

Danet S, Richard F, Montaye M, Beauchant S and 5 others (1999) Unhealthy effects of atmospheric temperature and pressure on the occurrence of myocardial infarction and coronary deaths. A 10-year survey: the Lille-World Health Organization MONICA project (Monitoring trends and determinants in cardiovascular disease). Circulation 100:E1-E7

Davis RE, Knappenberger PC, Novicoff WM, Michaels PJ (2002) Decadal changes in heat-related human mortality in the Eastern US. Clim Res 22:175-184

Davis RE, Knappenberger PC, Novicoff WM, Michaels PJ (2003a) Decadal changes in summer mortality in U.S. cities. Int J Biometeorol 47:166-175

Davis RE, Knappenberger PC, Michaels PJ, Novicoff WM (2003b) Changing heat-related mortality in the United States. Environ Health Perspect 111:1712-1718

Donaldson GC, Keatinge WR (1997) Early increases in ischaemic heart disease mortality dissociated from and later changes associated with respiratory mortality after cold weather in south east England. J Epidemiol Comm Health 51:643-648

Donaldson GC, Ermakov SP, Komarov YM, McDonald CP, Keatinge WR (1998) Cold related mortalities and protection against cold in Yakutsk, eastern Siberia: observation and interview study. Br Med J 317:978-982

Eng H, Mercer JB (1998) Seasonal variations in mortality caused by cardiovascular diseases in Norway and Ireland. J Cardiovascular Risk 5:89-95

Eurowinter Group (1997) Cold exposure and winter mortality from ischaemic heart disease, cerebrovascular disease, respiratory disease, and all causes in warm and cold regions of Europe. Lancet 349:1341-1346

Frost DB, Auliciems A (1993) Myocardial infarct death, the population at risk, and temperature habituation. Int J Biometeorol 37:46-51

Glass R, Zack M (1979) Increase in deaths from ischemic heart disease after blizzards. Lancet 3:485-487

Gorjanc ML, Flanders WD, VanDerslice J, Hersh J, Malilay J (1999) Effects of temperature and snowfall on mortality in Pennsylvania. Am J Epidemiol 149:1152-1160

Gover M (1938) Mortality during periods of excessive temperature. Public Health Rep 53:1122-1143

Guest CS, Willson K, Woodward AJ, Hennessy K, Kalkstein LS, Skinner C, McMichael AJ (1999) Climate and mortality in Australia: retrospective study, 1979-1990, and predicted impacts in five major cities in 2030. Clim Res 13:1-15

Hayden BP (1998) Ecosystem feedbacks on climate at the landscape scale. Phil Trans R Soc Lond Ser B 352:5-18

IPCC (2001a) Climate change 2001: impacts, adaptation, and vulnerability. Contribution of Working Group II. In: McCarthy JJ, Osvaldo FC, Leary NA, Dokken DJ, White KS (eds) Third Assessment Report of the Intergovernmental Panel on Climate Change. Cambridge University Press, Cambridge

IPCC (2001b) Climate change 2001: the scientific basis. Contribution of Working Group I. In: Houghton JT, Ding Y, Griggs DJ, Noguer M, van der Linden PJ, Dai X, Maskell K, Johnson CA (eds) Third Assessment Report of the Intergovernmental Panel on Climate Change. Cambridge University Press, Cambridge

Kalkstein LS (1993) Health and climate change-direct impacts in cities. Lancet 342:1397-1399
Kalkstein LS, Davis RE (1989) Weather and human mortality: an evaluation of demographic and interregional responses in the United States. Ann Assoc Am Geogr 79:44-64

Kalkstein LS, Greene JS (1997) An evaluation of climate/mortality relationships in large U.S. cities and the possible impacts of a climate change. Environ Health Perspect 105: 84-93

Kalkstein LS, Smoyer KE (1993) The impact of climate change on human health: some international implications. Experientia 49:969-979

Kalnay E, Cai M (2003) Impact of urbanization and land-use change on climate. Nature 423:528-531

Kilbourne EM (1997) Heat waves and hot environments. In: Noji EK (ed) The public health consequences of disaster. Oxford University Press, New York, p 245-269

Kloner RA, Poole WK, Perritt RL (1999) When throughout the year is coronary death most likely to occur? A 12-year population-based analysis of more than 220,000 cases. Circulation 100:1630-1634

Kunst AE, Looman CWN, Mackenbach JP (1993) Outdoor air temperature and mortality in the Netherlands: a time series analysis. Am J Epidemiol 137:331-341

Langford IH, Bentham G (1995) The potential effects of climate change on winter mortality in England and Wales. Int J Biometeorol 38:141-147

Lanska DJ, Hoffmann RG (1999) Seasonal variation in stroke mortality rates. Neurology 52:984-990

Larsen U (1990a) The effects of monthly temperature fluctuations on mortality in the United States from 1921 to 1985. Int J Biometeorol 34:136-145

Larsen U (1990b) Short-term fluctuations in death by cause, temperature, and income in the United States 1930-1985. Soc Biol 37:172-187

Laschewski G, Jendritzky G (2002) Effects of the thermal environment on human health: an investigation of 30 years of daily mortality data from SW Germany. Clim Res 21:91-103

Lerchl A (1998) Changes in the seasonality of mortality in Germany from 1946 to 1995: the role of temperature. Int J Biometeorol 42:84-88

Lyster WR (1976) Death in summer [letter]. Lancet 2:469

Marmor M (1975) Heat wave mortality in New York City, 1949 to 1970. Arch Environ Health 30:130-136

McGregor GR (1999) Winter ischaemic heart disease deaths in Birmingham, UK: a synoptic climatological analysis. Clim Res 13:17-31

McGregor GR (2001) The meteorological sensitivity of ischaemic heart disease mortality events in Birmingham, UK. Int J Biometeorol 45:133-142

McGregor GR, Watkin HA, Cox M (2004) Relationships between the seasonality of temperature and ischaemic heart disease mortality: implications for climate based health forecasting. Clim Res 25:253-263

Michaels PJ, Balling Jr RC (2000) The satanic gases: clearing the air about global warming. Cato Institute, Washington, DC

Michaels PJ, Balling Jr RC, Vose RS, Knappenberger PC (1998) Analysis of trends in the variability of daily and monthly historical temperature measurements. Clim Res 10:27-33

Moore TG (1998) The health and amenity benefits of global warming. Econ Inquiry July:471-488

National Assessment Synthesis Team (2000) Climate change impacts on the United States: the potential consequences of climate variability and change. US Global Change Research Program, Washington, DC

National Center for Health Statistics (1998) Compressed mor- 
tality file. US Dept Health Human Service, Public Health Service, CDC, Atlanta, GA

National Climatic Data Center (1993) Solar and meteorological surface observation network 1961-1990. National Climatic Data Center, Asheville, NC

National Climatic Data Center (1997) Hourly United States weather observations 1990-1995. National Climatic Data Center, Asheville, NC

National Environmental Satellite, Data, and Information Service (2000) TD-3280 US Surface Airways and Airways Solar Radiation Hourly. US Department of Commerce, Washington, DC

Oechsli FW, Buechley RW (1970) Excess mortality associated with three Los Angeles September hot spells. Environ Res 3:277-284

Osczevski RJ (1995) The basis of wind chill. Arctic 48: 372-382

Pell JP, Cobbe SM (1999) Seasonal variations in coronary heart disease. Q J Med 92:689-696

Quayle RG, Steadman RG (1998) The Steadman wind chill: an improvement over present scales. Weather Forecast 13: $1187-1193$

Sakamoto-Momiyama M (1977) Seasonality in human mortality. University of Tokyo Press, Tokyo

Schuman SH (1972) Patterns of urban heat-wave deaths and implications for prevention: data from New York and St. Louis during July, 1966. Environ Res 5:59-75

Editorial responsibility: Andrew Comrie,

Tucson, Arizona, USA
Schuman SH, Anderson CP, Oliver JT (1964) Epidemiology of successive heat waves in Michigan in 1962 and 1963. J Am Med Assoc 180:131-136

Seretakis D, Lagiou P, Lipworth L, Signorello LB, Rothman KJ, Trichopoulos D (1997) Changing seasonality of mortality from coronary heart disease. J Am Med Assoc 278: 1012-1014

Simonsen L, Clarke MJ, Williamson GD, Stroup DF, Arden NH, Schonberger LB (2001) The impact of influenza epidemics on mortality: introducing a severity index. Am J Pub Health 87:1944-1950

Smoyer KE (1993) Socio-demographic implications in summer weather-related mortality. MA thesis, University of Delaware, Newark

Smoyer KE, Rainham GC, Hewko JN (2000) Heat-stressrelated mortality in five cities in Southern Ontario: 1980-1996. Int J Biometeorol 44:190-197

Steadman RG (1971) Indices of wind chill of clothed persons. J Appl Meteorol 10:674-683

Thompson WM, Shay DK, Weintraub E, Brammer L, Cox N, Anderson LJ, Fukuda K (2003) Mortality associated with influenza and respiratory syncytial virus in the United States. J Am Med Assoc 289:179-186

United States Department of Commerce (1973, 1982, 1992, 2001) General population characteristics, United States. US Department of Commerce, Bureau of the Census, Washington, DC

Submitted: June 26, 2003; Accepted: February 23, 2004 Proofs received from author(s): April 2, 2004 